\title{
DNA Degradation and Its Defects
}

\author{
Kohki Kawane ${ }^{1}$, Kou Motani ${ }^{1}$, and Shigekazu Nagata ${ }^{1,2}$ \\ ${ }^{1}$ Department of Medical Chemistry, Kyoto University Graduate School of Medicine, Yoshida-Konoe, Kyoto \\ 606-8501, Japan \\ ${ }^{2}$ Core Research for Evolutional Science and Technology, Japan Science and Technology Corporation, \\ Yoshida-Konoe, Kyoto 606-8501, Japan \\ Correspondence: snagata@mfour.med.kyoto-u.ac.jp
}

DNA is one of the most essential molecules in organisms, containing all the information necessary for organisms to live. It replicates and provides a mechanism for heredity and evolution. Various events cause the degradation of DNA into nucleotides. DNA also has a darker side that has only recently been recognized; DNA that is not properly degraded causes various diseases. In this review, we discuss four deoxyribonucleases that function in the nucleus, cytosol, and lysosomes, and how undigested DNA causes such diseases as cancer, cataract, and autoinflammation. Studies on the biochemical and physiological functions of deoxyribonucleases should continue to increase our understanding of cellular functions and human diseases.

$\mathrm{C}$ hromosomal DNA replicates semiconservatively; it is constructed in growing cells and is not thereafter metabolized within the cell. Both animal and plant cells carry several DNA-degrading enzymes (called deoxyribonuclease, or DNase). DNases have primarily been regarded as enzymes that digest the DNA in food into nucleotides for use in rebuilding the organism's own DNA, just as proteases digest food proteins (from fish, meat, or vegetables) into amino acids. For many years, studies on DNases focused almost exclusively on their enzymatic activity, and not on their physiological or pathological roles. This changed with the discovery that chromosomal DNA is digested in apoptotic cells (Wyllie 1980). Since then, DNA degradation has been observed in the differentiation processes of red blood cells, skin, and optic lens (Bassnett 2002; McGrath et al. 2008; Eckhart et al. 2013). Reverse-transcribed DNA from endogenous retro elements is digested in the cytoplasm (Stetson et al. 2008), and in inflammation, extracellular DNA released from dead cells is actively degraded in the circulation (Rekvig and Mortensen 2012). Here, we discuss how DNA is digested in physiological and pathological settings, and what happens to the organism if DNA is not properly digested.

\section{A DNase THAT CLEAVES DNA IN THE NUCLEUS \\ Apoptosis}

Apoptosis destroys surplus cells generated during animal development, cells infected with a virus or bacteria, tumor cells, and senescent

Editor: Ruslan M. Medzhitov

Additional Perspectives on Innate Immunity and Inflammation available at www.cshperspectives.org

Copyright (C) 2014 Cold Spring Harbor Laboratory Press; all rights reserved; doi: 10.1101/cshperspect.a016394

Cite this article as Cold Spring Harb Perspect Biol 2014;6:a016394 
K. Kawane et al.

cells in a process involving cell shrinkage, chromatin condensation, and membrane blebbing (Jacobson et al. 1997; Strasser et al. 2009). Apoptosis occurs at a rate of a few million cells each second in the human body. It can be triggered by death factors, anticancer drugs, $\gamma$-ray irradiation, or deprivation of essential factors. Whatever the trigger may be, apoptosis is in most cases executed by caspases, a cysteine proteases family consisting of 14 members that are divided into initiator and effector caspases. Each caspase recognizes a specific sequence of four amino acids, and specifically cleaves proteins after an aspartic acid. Death factors such as Fas ligand (FasL), TNF (tumor necrosis factor), and TRAIL (TNF-related apoptosis-inducing factor) bind their receptors (Fas, TNF-R1, and DR4 and DR5, respectively) to activate caspase8 via an adaptor, Fas-associated protein with death domain. Caspase-8 activates caspase-3 and caspase-7, alone or together, by cleaving their precursors. Anticancer drugs, $\gamma$-ray irradiation, and factor deprivation, trigger apoptosis by activating BH3-only proteins of the Bcl-2 family, such as Bim, Bad, or Noxa. These in turn activate Bax or Bak (also members of the Bcl-2 family), prompting mitochondria to release cytochrome $c$, which works with APAF-1 to activate caspase-9. Caspase- 9 activates caspase-3 and caspase-7, individually or together. Caspase- 3 and caspase-7 are effector caspases that cleave more than 400 substrates to affect apoptosis and kill the cell (Nagata 1997; Susin et al. 2000; Dix et al. 2008; Mahrus et al. 2008).

\section{Caspase-Activated DNase}

The DNase responsible for apoptotic DNA fragmentation is CAD (caspase-activated DNase), also called DFF-40 (DNA fragmentation factor 40) (Nagata 2005). In healthy cells, CAD is locked in a complex with its inhibitor, ICAD (inhibitor of CAD), also called DFF-45 (DNA fragmentation factor 45) (Liu et al. 1997; Enari et al. 1998; Sakahira et al. 1998). ICAD also acts as a molecular chaperone for CAD; it binds to the nascent $\mathrm{CAD}$ chain on the ribosomes, assists in folding the CAD protein, and remains with $\mathrm{CAD}$ when it is released from the ribosomes as a part of the CAD-ICAD complex (Sakahira et al. 2000; Sakahira and Nagata 2002). This sophisticated chaperone system for generating CAD, a potentially hazardous molecule with the ability to destroy DNA, guarantees fail-safe machinery for apoptotic DNA fragmentation. Because CAD cannot be produced without ICAD, apoptotic DNA fragmentation does not occur in $C A D$-null or ICAD-null cells (Zhang et al. 1998).

ICAD contains the caspase- 3 or caspase- 7 recognition sequence at two positions. When cells receive apoptotic stimuli, ICAD is cleaved by activated caspase-3 or caspase-7, releasing CAD as a homodimer with a scissor-like structure (Woo et al. 2004). The CAD dimer digests DNA at spacer regions between nucleosomes, whereas the chromatin structure is still intact, thus producing multimers of DNA fragments with nucleosomal units (Fig. 1). Apoptotic cells are detected by terminal deoxynucleotidyl transferase (TdT)-mediated dUTP nick-end labeling (TUNEL) staining (Gavrieli et al. 1992), in which the terminal transferase adds a nucleotide to a free hydroxyl group at the $3^{\prime}$ end of DNA fragments severed by CAD.

In apoptosis, chromosomal DNA is degraded in two steps: first into large $(50-100 \mathrm{~kb})$ units, and then into nucleosomal units. Regardless of the apoptotic stimuli or cell type, CAD is responsible for both steps because DNA degradation does not follow this pattern in $C A D$ or ICAD-null cells (Kawane et al. 2003; Nagase et al. 2003). Thus, other nucleases that have been reported to degrade DNA in apoptosis, such as endonuclease G, DNase $\gamma$, and AIF (Penninger and Kroemer 2003; Mizuta et al. 2009) have little, if any, role in this process. DNA fragmentation downstream from the caspase cascade has been thought to affect cell death. In fact, microinjecting activated CAD or CAD dimers into a healthy cell quickly kills it (Susin et al. 2000). However, apoptotic stimuli kill $C A D$ - or ICAD-null cells as efficiently as $C A D$ competent cells (Sakahira et al. 1998). This indicates that there are many ways to kill a cell once caspases have been activated, and that DNA fragmentation itself is dispensable for apoptotic cell death. 
DNA Degradation and Its Defects

A

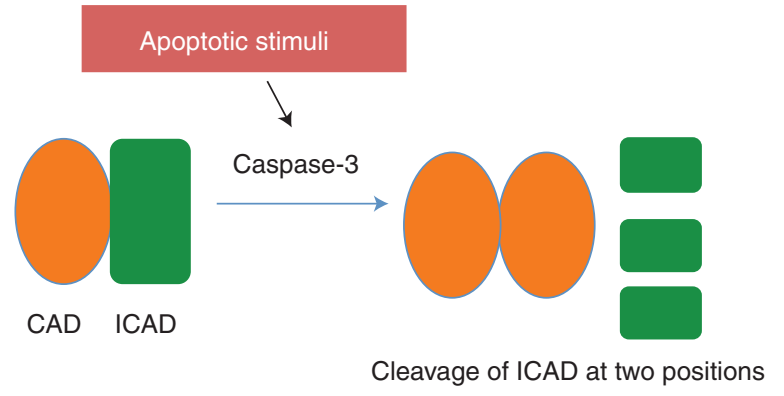

B

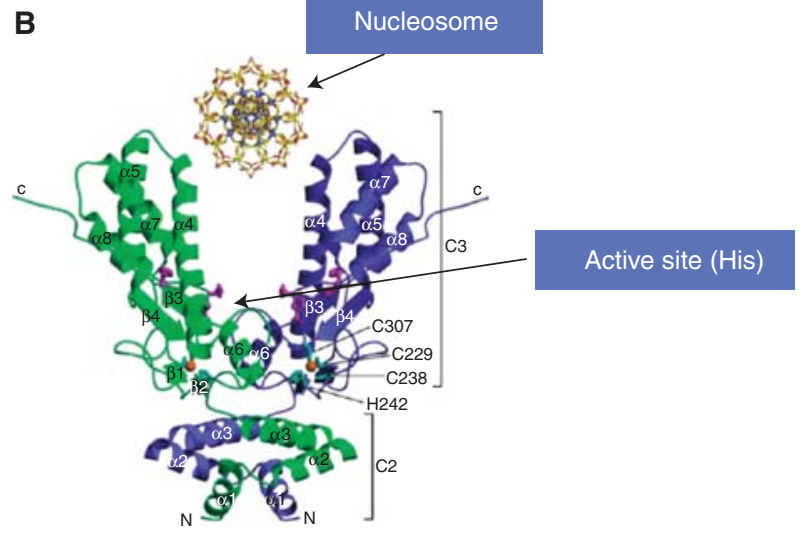

C
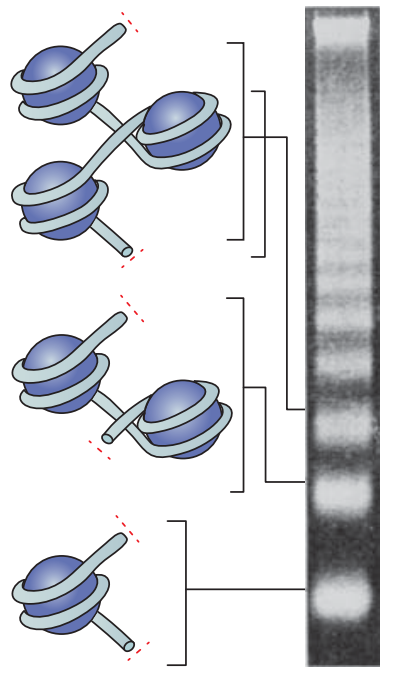

CAD dimer

Figure 1. CAD-mediated DNA fragmentation in apoptosis. In healthy cells, CAD (caspase-activated DNase) is present as a complex with ICAD (inhibitor of CAD). When cells receive apoptotic stimuli, caspase-3 cleaves ICAD at two positions, and the cleaved ICAD loses the affinity to CAD $(A)$. The activated CAD, or CAD freed from ICAD, forms a homodimer with a scissor-like structure, in which the active site carrying histidine residues is in the cleft. Because of the structure of the CAD dimer, DNA between nucleosomes, but not DNA on nucleosomes, has access to the active site of the enzyme $(B)$. This explains why chromosomal DNA is cleaved into nucleosomal units during apoptotic cell death $(C)$. (B is adapted from data in Woo et al. 2004.)

\section{Defective CAD Leads to Cancer and Autoimmune Disease}

Despite CAD's indispensable role in fragmenting DNA during apoptosis, $C A D$-null mice have no apparent gross abnormality (Kawane et al. 2003). On the other hand, the human $C A D$ and ICAD genes at chromosome 1p36.2 (Mukae et al. 1998) are aberrantly expressed in various human tumors, and are often mutated in neuroblastoma and germ cell tumors (Yang et al. 2001). CAD-deficient cells are sensitive to radiation-induced chromosome instability and are easily transformed into anchorage-independent tumor cells (Yan et al. 2006). Although CAD cleaves DNA randomly, its preferred targets largely overlap with sites where mutations are introduced in cancer cells (Fullwood et al. 2011), suggesting that CAD removes DNA mutated by DNA-damaging agents at an early stage of apoptosis. Tang et al. (2012) recently reported that apoptotic cells can be recovered to a viable state from even late stages of apoptosis. If CAD deficiency prevents the removal of damaged DNA, the damaged DNA sequences in cells rescued from apoptosis may cause cells to undergo transformation. CAD-mediated DNA fragmentation may also be involved in an amplification step of apoptosis (Boulares et al. 2001). In the apoptosis induced by specific agents, the CAD- 
K. Kawane et al.

fragmented DNA activates poly(ADP-ribose) polymerase, which quickly depletes the cellular NAD, efficiently executing the cells.

CAD also regulates autoimmunity. Apoptotic cells, or apoptotic bodies, induce autoantibody production in systemic lupus erythematosus (SLE)-type autoimmune diseases (CasciolaRosen et al. 1994). Jog et al. (2012) recently showed that a $C A D$-null mutation in lupusprone mice accelerates autoantigen production and aggravates renal disease, suggesting that CAD plays an important role in maintaining immunological tolerance against nuclear antigens. This interesting observation should lead to further investigations as to how this is accomplished.

\section{DNases IN LYSOSOMES}

\section{Engulfment of Apoptotic Cells}

by Macrophages

Cell-autonomous DNA fragmentation does not occur in $C A D$-deficient cells, yet tissues in $C A D$ deficient mice do not accumulate undigested DNA. Close examination of $C A D$-null tissues revealed that the DNA from dead cells is degraded in the lysosomes of macrophages (Mcllroy et al. 2000). The macrophages recognize an "eat me" phosphatidylserine (PtdSer) signal on apoptotic cells and swiftly engulf the dying cells (Fadok et al. 1992), preventing the release of noxious materials. PtdSer, one of the most abundant phospholipids in the plasma membrane, is kept tightly in the inner leaflet of the plasma membrane in healthy cells (Leventis and Grinstein 2010). We recently showed that when cells undergo apoptosis, caspase- 3 or -7 cleaves off the carboxy-terminal tail of Xkr8, a plasmamembrane protein with six transmembrane regions (Suzuki et al. 2013). Xkr8 then mediates phospholipid scrambling between the inner and outer leaflets of the plasma membrane, exposing PtdSer on the cell surface as an "eat me" signal.

Macrophages express PtdSer receptors such as Tim4, BAI1, and stabillin2 (Miyanishi et al. 2007; Park et al. 2007, 2008), and Tim4 has been shown to function in the binding or tethering of apoptotic cells (Toda et al. 2012). The apoptotic cells tethered by Tim 4 are transferred to $\alpha_{\mathrm{v}} \beta_{3}$ integrin or MER receptor tyrosine kinases of the TAM family via PtdSer-binding opsonins, such as MFG-E8 and Gas6 that are secreted from macrophages (Scott et al. 2001; Hanayama et al. 2002; Xiong et al. 2008). Apoptotic cells are then internalized by macrophages via "phagocytic cups" assembled by Rac1-dependent actin polymerization (Kinchen and Ravichandran 2007; Nakaya et al. 2008), and are transported into lysosomes via early endosomes by the small GTPase Rab5 (Kitano et al. 2008). Lysosomes contain a variety of degradative enzymes (proteases, glycosidases, lipases, and nucleases) that digest components from dead cells into building units for reuse (amino acids, sugars, fatty acids, and nucleotides) (von Figura and Hasilik 1986).

DNase II and Its Degradation of the DNA of Apoptotic Cells

The enzyme that digests DNA in macrophage lysosomes is deoxyribonuclease II (DNase II), also called DNase II $\alpha$ or acid DNase, which has the optimal $\mathrm{pH}$ at acid condition (Evans and Aguilera 2003). DNase $\mathrm{II}^{-/-}$mouse embryos carry numerous peculiar macrophages, filled with Feulgen-positive DNA in various tissues where apoptosis occurs extensively during development (Kawane et al. 2001, 2003; Krieser et al. 2002). Electron microscope analyses suggested that the DNase $\mathrm{II}^{-/-}$macrophages engulf apoptotic cells and digest all of the cell components except DNA. The DNA that accumulates in the lysosomes of DNase $\mathrm{II}^{-/-}$macrophages is fragmented and strongly TUNELpositive. However, the DNA that accumulates in the macrophages of $\mathrm{CAD}^{-/-}$DNase $\mathrm{II}^{-/-}$ double knockout embryos appears intact, and is not stained by TUNEL. These results confirm that the DNA in the apoptotic cells is digested in two steps: first, it is fragmented into nucleosomal units by CAD in the apoptotic cells, and then it is completely digested into nucleotides by DNase II in the lysosomes of the engulfing macrophage (Kawane et al. 2003). DNase II in C. elegans is called Nuc-1, and both a Nuc-1-null mutation in C. elegans (Wu et al. 2000) and a DNase II-null mutation in Drosophila (Mukae 
et al. 2002) strongly enhance the TUNEL positivity. This suggests that the mechanism of twostep apoptotic DNA degradation is evolutionarily well conserved, although DNase II may also function cell-autonomously in the nonapoptotic cell death of nurse cells in late oogenesis in Drosophila (Bass et al. 2009).

\section{Degradation of Pyrenocyte DNA by DNase II}

Each day, our bodies generate about 200 billion red blood cells, at least 10 times number of cells undergoing apoptosis. In the DNase $\mathrm{II}^{-/-} \mathrm{em}$ bryo, a large number of macrophages carrying undigested DNA in their lysosomes are found in the fetal liver (Kawane et al. 2001; Krieser et al. 2002), where definitive erythropoiesis takes place in late embryogenesis (Palis 2008). The macrophages carrying DNA are the central macrophages in erythroblastic islands, where the erythropoiesis takes place (Chasis and Mohandas 2008). Erythroblasts proliferate and differentiate on these macrophages, and finally divide asymmetrically into reticulocytes and pyrenocytes (nucleus covered by plasma membrane) (McGrath et al. 2008; Rhodes et al. 2008). The pyrenocytes quickly expose PtdSer on their surface in a caspase-independent manner, and the macrophages in the center of the islands recognize PtdSer as the "eat-nucleus" signal and engulf the pyrenocytes (Yoshida et al. 2005a). DNase II in these erythroblastic islands is responsible for digesting the DNA $(\sim 1.0 \mathrm{~g})$ of 200 billion pyrenocytes per day.

\section{Defective DNase II Leads to}

\section{Autoinflammation Activation}

DNase II-null mice die of severe anemia in late embryogenesis (Kawane et al. 2001). Because T-cell development is arrested at the $\mathrm{CD} 4{ }^{-} \mathrm{CD} 8{ }^{-}$stage, the DNase II-null fetal thymus is one-third the size of the wild-type one (Kawane et al. 2003). A set of interferon-(IFN) inducible genes is strongly expressed in these mutant embryos (Kawane et al. 2003; Yoshida et al. 2005b). Accordingly, in situ hybridization indicated that the IFN- $\beta$ gene is expressed in macrophages carrying undigested DNA (Yoshida et al. 2005b). Type I IFNs, such as IFN$\beta$, are cytokines that confer virus resistance to cells (Borden et al. 2007) and that are cytotoxic to various cancer cells, erythroid cells, and T-cell precursors ( pro-T cells) (Su et al. 1997; GómezBenito et al. 2007; Jain and Zoellner 2010). The null mutation of $I F N-I R$, which encodes the type-I IFN receptor for IFN- $\alpha$ and IFN- $\beta$, rescues the lethality of DNase II-null embryos, and DNase $I I^{-/-} I F N-I R^{-/-}$mice are born at nearly a Mendelian ratio (Yoshida et al. 2005b). The number of peripheral red blood cells and the thymus size return to normal, indicating that if the engulfed DNA from apoptotic cells or pyrenocytes is not properly degraded in the macrophages, the IFN- $\beta$ gene is activated, causing lethal anemia and thymic atrophy.

The rescued DNase $I I^{-/-} I F N-I R^{-/-}$mice develop polyarthritis as they age (Kawane et al. 2006). At 5-7 months, all the joints show synovitis with well-established pannus, an inflammatory structure composed of synoviocytes, macrophages, fibroblasts, and infiltrated immune cells, and the cartilage and bone around the pannus are destroyed. If the DNase II gene is inducibly deleted, the mice develop arthritis with the same properties. The histology of the arthritis in DNase II-deficient mice resembles that of human rheumatoid arthritis (RA), a chronic inflammation characterized by a massive production of inflammatory cytokines in the joints (Scott et al. 2010). Similarly, inflammatory cytokines and chemokines are highly upregulated in the joints of DNase II-deficient mice, and high levels of rheumatoid factor, anticyclic citrullinated protein antibody, matrix metalloprotease-3 (MMP-3), and interleukin (IL)-18 are found in the serum. The DNase II-null mutation induces arthritis in various mice strains (C57BL6 and Balb/c) without gender preference. These properties of the arthritis in DNase II-null mice are similar to those observed in human systemic-onset juvenile idiopathic arthritis (soJIA, also called Still's disease) (Vastert et al. 2009). The arthritis in DNase IIdeficient mice does not require acquired immunity, but depends strongly on inflammatory cytokines. That is, although the loss of Rag2 
K. Kawane et al.

(recombination activation gene), which is essential for the $\mathrm{V}(\mathrm{D}) \mathrm{J}$ gene rearrangement in lymphocytes, has no effect on the arthritis (Kawane et al. 2010), the arthritis is almost completely blocked by deleting the $I L-1$ receptor, $I L-6$, or TNF- $\alpha$ genes (Kawane et al. 2010). Remarkably, a lack of one inflammatory cytokine blocks the expression of other cytokines in the joints; deleting the TNF- $\alpha$ gene blocks $I L-6$ and $I L-1 \beta$ expression, while deleting $I L-6$ gene blocks $T N F-\alpha$ and $I L-1 \beta$ expression, indicating that these inflammatory cytokines regulate the expression of other genes in the joint. Accordingly, administrating antibodies against TNF- $\alpha$, IL-1 receptor (IL-1R), or IL-6 receptor (IL-6R) efficiently cures the disease. This is similar to the therapeutic effect of anti-TNF- $\alpha$, anti-IL-6R, and anti-IL-1R antibodies in human soJIA patients.

In DNase II-deficient adult mice, macrophages carrying DNA in their lysosomes are present in the bone marrow and red splenic pulp, suggesting that cytokines produced in the macrophages induce arthritis at the joints. Because TNF- $\alpha$-transgenic mice develop arthritis (Keffer et al. 1991), TNF- $\alpha$ is a strong candidate for the arthritis trigger in DNase II-null mice. In fact, macrophages carrying undigested DNA in their lysosomes constitutively produce TNF- $\alpha$ (Kawane et al. 2006). It is likely that the TNF- $\alpha$ in turn stimulates the synovial cells in joints to produce cytokines such as IL-1 $\beta$, IL-6, granulocyte colony-stimulating factor (G-CSF), and chemokines. IL- $1 \beta$, TNF- $\alpha$, and IL- 6 in the articular cavity then activate synovial cells and fibroblasts to produce other inflammatory cytokines. Inflammatory cytokines and chemokines accumulate in high concentrations in the articular cavity, where they stimulate the growth of synovial cells and fibroblasts, and recruit lymphocytes, neutrophils, and macrophages into the joints. Pannus, thus formed, destroys cartilage and bones, and arthritis develops (Fig. 2).

DLAD, a DNase in Lens Fiber Cells

DLAD (DNase II-like acid DNase, also called DNase II $\beta$ ) has a $38 \%$ amino acid sequence identity with DNase II (Shiokawa and Tanuma 1999) and is also localized to the lysosomes (Nakahara et al. 2007). Unlike DNase II, which is ubiquitously expressed in various tissues and cells, DLAD is specifically expressed in fiber cells of the optic lens (Fig. 3) (Nishimoto et al. 2003). This avascular tissue, which focuses light onto the retina, consists of packed fiber cells bounded at the anterior by a monolayer of epithelial cells. The epithelial cells continuously differentiate into fiber cells near the lens equator, and as there is no cell turnover, the lens continues to grow throughout life (McAvoy et al. 1999). As the epithelial cells differentiate into fiber cells, they synthesize lens-fiber-specific proteins such as crystallins. The DLAD gene is also activated during this differentiation process (Nakahara et al. 2007).

This differentiation of epithelial cells to fiber cells in the eye is accompanied by the loss of intracellular organelles such as mitochondria and nuclei, to form a light-transmittable organ (Bassnett 2009). Organelles are degraded cellautonomously in the differentiating cells, and DLAD is responsible for degrading the DNA (Nishimoto et al. 2003). The lens fiber cells in $D L A D^{-/-}$mice carry undigested DNA in their cytoplasm, although all the other organelles and nuclear components are degraded normally (Fig. 3) (Nishimoto et al. 2003). This cellautonomous degradation of organelles in the lysosomes is similar to autophagy. However, no abnormalities have been observed in the lens fiber cells of mice carrying a mutation in the genes ( $\mathrm{atg}$ ) for autophagy. It is also possible that the lysosomal and nuclear membranes are broken when lens cells differentiate to allow DLAD to attack the chromosomal DNA. Elucidation of the mechanism behind organelle degradation during lens cell differentiation would be an interesting research challenge.

\section{A DNase THAT CLEAVES DNA IN THE CYTOSOL}

\section{TREX1 and Its Defect}

Trex1 (three prime repair exonuclease, also called DNase III), ubiquitously expressed in var- 
A

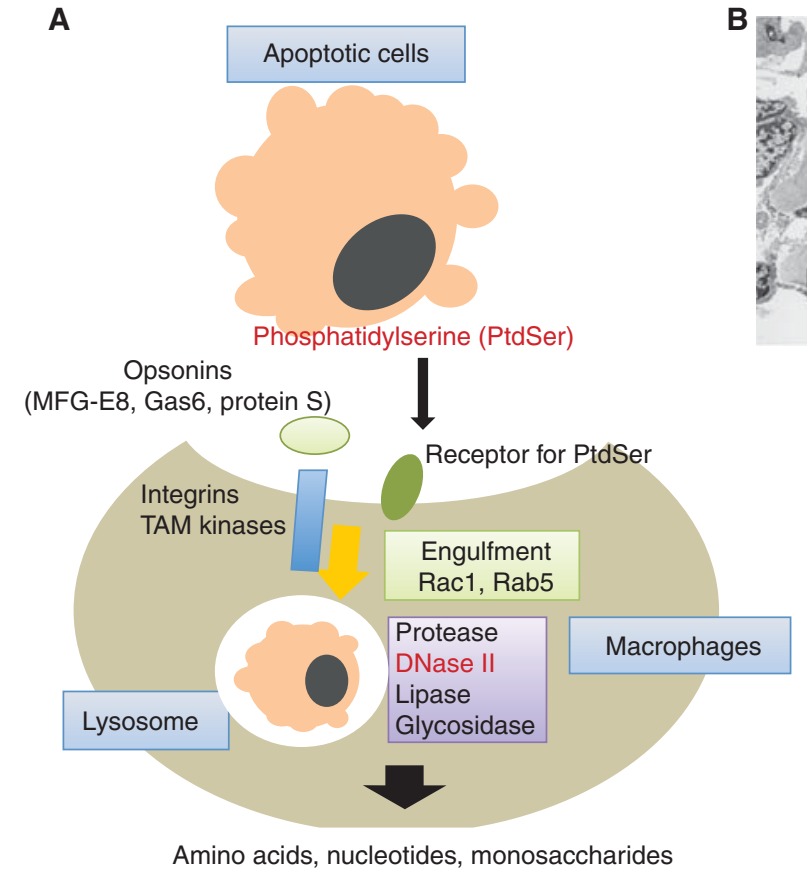

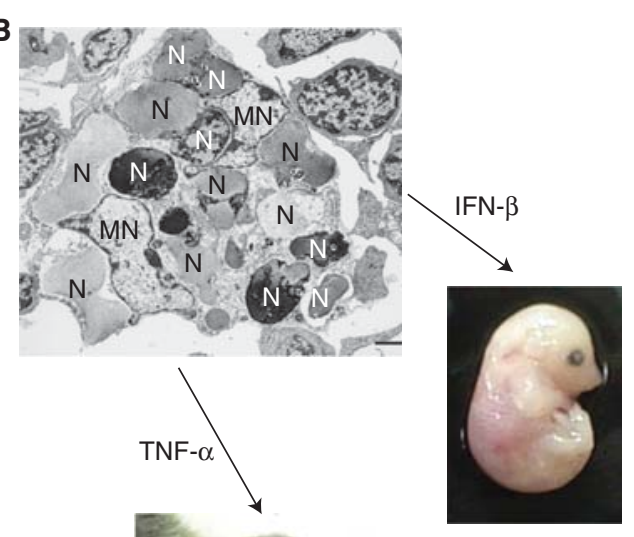

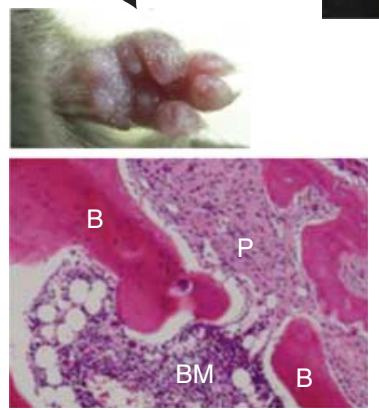

Figure 2. Engulfment of apoptotic cells by macrophages, and DNA degradation in lysosomes of macrophages. (A) Apoptotic cells expose phosphatidylserine (PtdSer) as an "eat me" signal, which is recognized by the PtdSer receptor (Tim4, Tim1, BAI1, and stabillin) expressed in macrophages. Apoptotic cells are engulfed by macrophages using the integrins and MER (TAM family kinases) system together with opsonins (MFG-E8, protein S, and Gas6) that bind PtdSer. The dead cells are then transported into lysosomes using the Rac1- and Rab5- mediated intracellular trafficking systems, and the dead cell components are degraded into amino acids, nucleotides, and monosaccharides. (B) The enzyme that digests DNA in macrophage lysosomes is DNase II. Macrophages in DNase $\mathrm{II}^{-/-}$embryos carry many undigested nuclei, and produce cytokines such as IFN- $\beta$ and TNF- $\alpha$. IFN- $\beta$ causes lethal anemia in mouse embryos, whereas TNF- $\alpha$ seems to be responsible for causing polyarthritis. ( $B$ is from Kawane et al. 2001; reprinted, with permission.)

ious cells, is the major $3^{\prime}$ exonuclease that cleaves mismatched and modified nucleotides. Because of its high homology with Escherichia coli DnaQ, Trex1 was originally identified as an enzyme that edits mismatched $3^{\prime}$ termini generated during DNA repair and DNA synthesis (Höss et al. 1999). However, Trexl is expressed in both proliferating and nonproliferating cells, and its null mutation does not increase spontaneous mutation or tumorigenicity in mice; these observations suggest that Trex1 is either not active in base excision repair, or that it acts redundantly with other $3^{\prime}$ exonucleases (Morita et al. 2004). On the other hand, after studying the origin of DNA fragments accumulated in
TREX1-null cells, Stetson et al. (2008) proposed that TREX1 cleaves the single-stranded DNA derived from retrotransposons. Retrotransposons are found in both humans and mice [L1 in humans, IAP (intracisternal particles), Etns (early transposons), and mammalian LTR-retrotransposons (MaLTRs) in mice], and comprise $\sim 42 \%$ of the total mass of the human genome (Ostertag and Kazazian 2001). Although most retrotransposons are inactive, some intact retrotransposons carry reverse transcriptase, thus autonomously or nonautonomously transposing the elements (Sassaman et al. 1997; Prak and Kazazian 2000). The DNA is reversetranscribed from RNA in the cytoplasm, and 
K. Kawane et al.

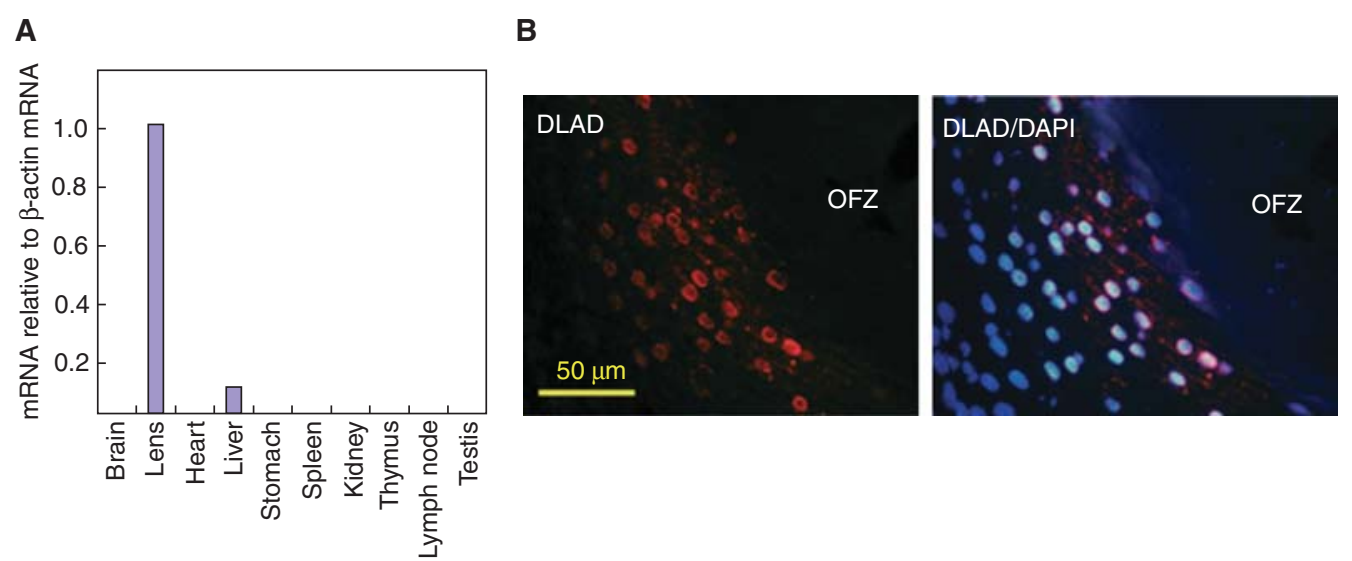

C
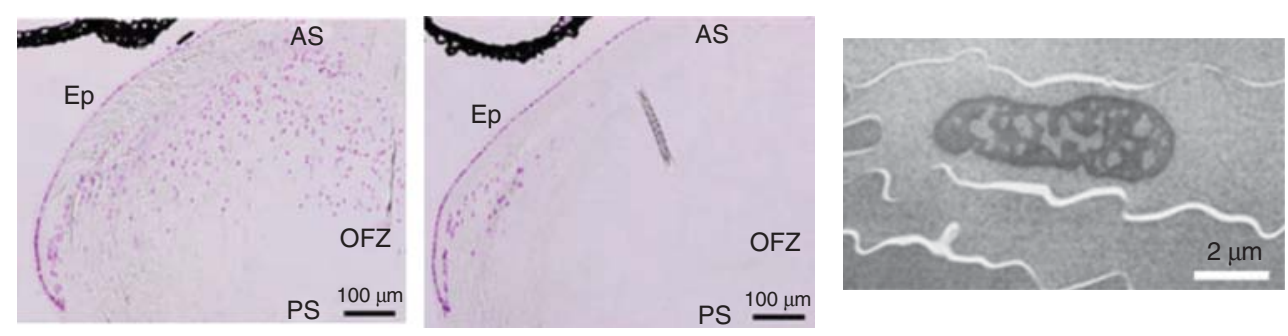

Figure 3. Degradation of DNA in lens fiber cells. DLAD (DNase II $\beta$ ) is exclusively expressed in eye lens $(A)$. Its expression is induced during differentiation of lens epithelial cells into fiber cells. The DLAD protein is found at the cortical fiber cells that surround organelle-free zone (OFZ) $(B)$, suggesting that it is expressed at the final stage of the lens cell differentiation. The lens fiber cells in $D L A D^{-}{ }^{-}$(left panel), but not wild-type (middle panel), mice have Feulgen-positive DNA in their cytoplasm (right panel; observed by an electron microscope) $(C)$, indicating that DLAD is responsible for the cell-autonomous digestion of DNA in fiber cells. ( $A$ and $C$ from Nishimoto et al. 2003; reprinted, with permission; $B$ from Nakahara et al. 2007; reprinted, with permission.)

the TREX1 nuclease appears to be responsible for digesting this DNA (Fig. 4) (Stetson et al. 2008).

Aicardi-Goutières syndrome, a human disease characterized by cerebral atrophy, intracranial calcifications, and lymphocytosis with high IFN- $\alpha$ levels in the cerebrospinal fluid, is caused by a Trex 1 loss-of function (Crow and Rehwinkel 2009). Undigested single-stranded DNA that can activate IFN- $\beta$ gene in Trex $1^{-/-}$cells (Yan et al. 2010) is found in the cytoplasm of various cells in Trex1-deficient mice (Stetson et al. 2008). The Trex1 $1^{-/-}$mice develop a lethal, IFN- $\alpha$-dependent inflammatory myocarditis (Morita et al. 2004). These properties associated with the strong inflammation by IFN- $\beta$ are similar to those in DNase II-null mice.

\section{INTRACELLULAR SIGNALING, DNA-TO-GENE EXPRESSION}

\section{Signal Transduction}

DNase II- or Trex1-null mice develop autoinflammation leading to anemia, arthritis, and myocarditis. In this process, undigested DNA induces the expression of cytokine genes such as type I IFN and TNF- $\alpha$. Pathogenic viruses and bacteria are extracellularly or intracellularly recognized by pattern-recognition receptors (PRRs), leading to cytokine production (Medzhitov 2007; Ronald and Beutler 2010; Takeuchi and Akira 2010). Toll-like receptor (TLR) PRRs, a family of type I membrane proteins, recognize pathogenic bacteria or viruses and activate type I IFN and TNF- $\alpha$ genes through the transcrip- 
DNA Degradation and Its Defects

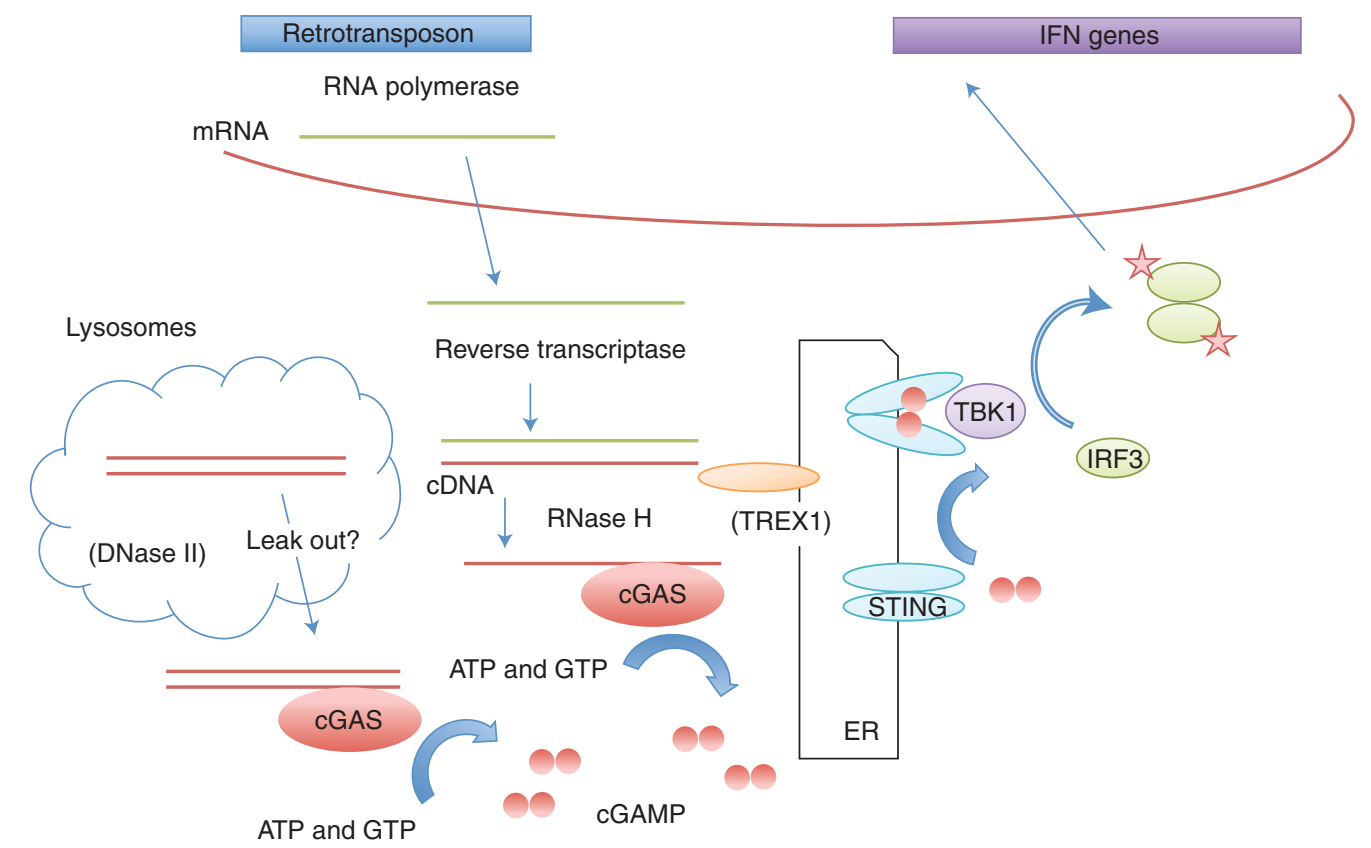

Figure 4. DNA-induced gene expression. Human and mouse cells contain in their genome many retrotransposons that are transcribed by RNA polymerase II into RNA. The RNA is transported into cytoplasm, and reversetranscribed into cDNA. The complementary DNA (cDNA). The cDNA is usually digested by TREX1 exonuclease at the endoplasmic reticulum (ER). When TREX1 cannot work, the cDNA activates cGAMP synthase (CGAS) to synthesize cGAMP from ATP and GTP. The cGAMP binds to STING at ER, and induces its conformational change from inactive to active dimers, which provides a scaffold for TBK1 kinase to phosphorylate IRF3 transcription factor. The phosphorylated IRF3 dimerizes and enters the nucleus to activate type I IFN genes. The undigested DNA accumulated in the lysosomes of DNase $I^{-/-}$macrophages may leak out from lysosomes and activate the type I IFN genes using the signal transduction described above.

tion factors IFN regulatory factor (IRF) 3/IRF7 and NF-кB. The IRF3/IRF7 double mutation rescues the lethality in DNase II-null embryos, indicating that the undegraded DNA in lysosomes leads to IRF3/IRF7 activation (Okabe et al. 2008). However, the double-null mutations of the TLR adaptors Myd88 and TRIF do not affect the lethality in DNase $\mathrm{II}^{-/-}$embryos, indicating that the TLR system is not involved in activating the IFN- $\beta$ gene in macrophages carrying undigested DNA (Okabe et al. 2005). On the other hand, STING null mutations fully rescue the lethality in DNase $I^{-/-}$embryos, although they do not reduce the number of macrophages carrying undigested DNA in the bone marrow (Ahn et al. 2012). Similarly, STING ${ }^{-/-}$Trex1 $1^{-/-}$mice do not develop myocarditis (Gall et al. 2012). STING, also called TMEM173, is a transmembrane protein at the endoplasmic reticulum that is essential for the innate immune response against DNA and RNA viruses such as HSV, HIV, and RSV (Ishikawa and Barber 2008; Ishikawa et al. 2009). Once activated, STING forms a functional dimer and, together with the adaptor protein IPS-1, stimulates the protein kinases IKK and TBK1 to activate the transcription factors NF- $\mathrm{BB}$ and IRF3, respectively (Tanaka and Chen 2012). Eyes absent (EYA), a dual phosphatase, also binds IPS-1 and regulates DNAinduced innate immunity (Okabe et al. 2009). These results suggest that if DNA from retrotransposons, apoptotic cells, or pyrenocytes is not properly digested, it activates the innate immunity via the cytosolic pathogen-recognition system. The lysosomes carrying undigested 
K. Kawane et al.

DNA in DNase $\mathrm{II}^{-/-}$macrophages are not apparently damaged, but the recently recognized labile nature of lysosomes (Terman et al. 2006) suggests that some DNA leaks from the lysosomes into the cytoplasm.

\section{DNA Sensors}

Cytosolic DNA must be recognized as a danger signal in the cytoplasm to activate the type I IFN and TNF- $\alpha$. Many molecules have been proposed to be DNA sensors, including DAI, DDX41, DHX36, DHX9, IFI16, AIM2, Mre11, and HMGB1 (Desmet and Ishii 2012; Paludan and Bowie 2013). The ability of STING to directly bind DNA has also been reported (Abe et al. 2013). Among these sensors, Aim2 was convincingly shown to bind bacterial or viral DNA and to activate inflammasomes in macrophages to produce IL-1 $\beta$ and IL-18 (FernandesAlnemri et al. 2010; Rathinam et al. 2010), and is not for the production of type I IFN and TNF$\alpha$. Dr. Zhijian Chen's laboratory recently published a series of elegant papers demonstrating that cyclic GMP-AMP (cGAMP), a dicyclic nucleotide, is a second messenger for DNA-driven signal transduction (Gao et al. 2013; Li et al. 2013; Sun et al. 2013; Wu et al. 2013). They show that DNA from DNA viruses or reversetranscribed from retrovirues binds to cGAMP synthase (cGAS), activating its enzymatic activity to catalyze the synthesis of cGAMP, which contains both $2^{\prime}-5^{\prime}$ and $3^{\prime}-5^{\prime}$ phosphodiester linkages (O’Neill 2013; Xiao and Fitzgerald 2013). Binding of cGAMP to STING induces its conformational changes to an active dimer, providing a scaffold for TBK1 kinase. Thus, the cGAMP-cGAS system is likely to function as a DNA sensor for the production of type I IFN and TNF- $\alpha$ in DNase II-null and Trex1-null mice (Fig. 4).

\section{CONCLUDING REMARKS}

Here, we reviewed four DNases, CAD, DNase II, DLAD, and Trex1, and diseases caused by their defects. CAD and DLAD defects cause cancer and cataracts, respectively. Considering the purposes of apoptosis and lens cell differentiation to remove damaged or dangerous cells, and to establish transparency, respectively, it is not surprising to find cancers and cataracts in animals that lack CAD or DLAD. On the other hand, the activation of inflammatory cytokine genes in DNase II- and Trex1-null mice appears to be a response to danger signals. The intracellular signal transduction system by which endogenous DNA activates the inflammatory cytokine genes seems to be identical to that used for bacterial or viral DNA. Bacterial or viral infection is often transient, and inflammation subsides when the infection is cleared. However, apoptotic cell death and definitive erythropoiesis continue throughout our lives. Retrotranspositions appear to be constitutive, as well. Thus, if DNase II or Trex1 does not function properly, cytokine genes are constitutively activated, resulting in chronic inflammation that can cause anemia, arthritis, or myocarditis. If the signaling pathway is identical in DNase II- and Trex1-null mice, it is not clear why one DNase defect causes arthritis, whereas the defect of another causes myocarditis; it may be because DNase II-mediated DNA degradation occurs mainly in the macrophages, whereas Trex1-mediated degradation occurs in all cell types. In this regard, it may be noteworthy that mice with a cardiacspecific DNase II deletion develop severe myocarditis and dilated cardiomyopathy when subjected to pressure overload (Oka et al. 2012).

There are many other DNases besides the four we have discussed. DNase I, a secreted DNase, is present in the blood serum. A lossof-function DNase I mutation in mice (Napirei et al. 2004), and its heterozygous mutation in humans causes SLE-type autoimmune disease (Yasutomo et al. 2001), indicating that undigested extracellular DNA can activate acquired immunity. Endonuclease G, a DNase localized to the mitochondria, was suggested to be involved in apoptotic DNA degradation ( $\mathrm{Li}$ et al. 2001). However, it was recently shown that endonuclease G stimulates DNA synthesis in mitochondria, and its defect impairs cardiac function (McDermott-Roe et al. 2011). Thus, various DNases are involved in different aspects of cell metabolism, and studies on the biochemical and physiological functions of DNases 
should contribute to our understanding of human diseases.

\section{ACKNOWLEDGMENTS}

We are grateful to members of our laboratory in the Graduate School of Medicine, Kyoto University. Work in our laboratory is supported in part by Grant-in-Aid from the Ministry of Education, Science, and Culture in Japan.

\section{REFERENCES}

Abe T, Harashima A, Xia T, Konno H, Konno K, Morales A, Ahn J, Gutman D, Barber GN. 2013. STING recognition of cytoplasmic DNA instigates cellular defense. Mol Cell 50: $5-15$.

Ahn J, Gutman D, Saijo S, Barber GN. 2012. STING manifests self DNA-dependent inflammatory disease. Proc Natl Acad Sci 109: 19386-19391.

Bass BP, Tanner EA, Mateos San Martín D, Blute T, Kinser RD, Dolph PJ, McCall K. 2009. Cell-autonomous requirement for DNaseII in nonapoptotic cell death. Cell Death Differ 16: 1362-1371.

Bassnett S. 2002. Lens organelle degradation. Exp Eye Res 74: $1-6$.

Bassnett S. 2009. On the mechanism of organelle degradation in the vertebrate lens. Exp Eye Res 88: 133-139.

Borden EC, Sen GC, Uze G, Silverman RH, Ransohoff RM, Foster GR, Stark GR. 2007. Interferons at age 50: Past, current and future impact on biomedicine. Nat Rev Drug Discov 6: 975-990.

Boulares AH, Zoltoski AJ, Yakovlev A, Xu M, Smulson ME. 2001. Roles of DNA fragmentation factor and poly(ADPribose) polymerase in an amplification phase of tumor necrosis factor-induced apoptosis. J Biol Chem 276: 38185-38192.

Casciola-Rosen LA, Anhalt G, Rosen A. 1994. Autoantigens targeted in systemic lupus erythematosus are clustered in two populations of surface structures on apoptotic keratinocytes. J Exp Med 179: 1317-1330.

Chasis JA, Mohandas N. 2008. Erythroblastic islands: Niches for erythropoiesis. Blood 112: 470-478.

Crow Y, Rehwinkel J. 2009. Aicardi-Goutières syndrome and related phenotypes: Linking nucleic acid metabolism with autoimmunity. Hum Mol Genet 18: R130-R136.

Desmet CJ, Ishii KJ. 2012. Nucleic acid sensing at the interface between innate and adaptive immunity in vaccination. Nat Rev Immunol 12: 479-491.

Dix MM, Simon GM, Cravatt BF. 2008. Global mapping of the topography and magnitude of proteolytic events in apoptosis. Cell 134: 679-691.

Eckhart L, Lippens S, Tschachler E, Declercq W. 2013. Cell death by cornification. Biochim Biophys Acta 1833: 3471 3480.

Enari M, Sakahira H, Yokoyama H, Okawa K, Iwamatsu A Nagata S. 1998. A caspase-activated DNase that degrades
DNA during apoptosis, and its inhibitor ICAD. Nature 391: $43-50$.

Evans CJ, Aguilera RJ. 2003. DNase II: Genes, enzymes and function. Gene 322: 1-15.

Fadok VA, Voelker DR, Campbell PA, Cohen JJ, Bratton DL, Henson PM. 1992. Exposure of phosphatidylserine on the surface of apoptotic lymphocytes triggers specific recognition and removal by macrophages. J Immunol 148: 2207-2216.

Fernandes-Alnemri T, Yu J-W, Juliana C, Solorzano L, Kang S, Wu J, Datta P, McCormick M, Huang L, McDermott E, et al. 2010. The AIM2 inflammasome is critical for innate immunity to Francisella tularensis. Nat Immunol 11: 385-393.

Fullwood MJ, Lee J, Lin L, Li G, Huss M, Ng P, Sung W-K, Shenolikar S. 2011. Next-generation sequencing of apoptotic DNA breakpoints reveals association with actively transcribed genes and gene translocations. PLOS ONE 6: e26054.

Gall A, Treuting P, Elkon KB, Loo Y-M, Gale M, Barber GN, Stetson DB. 2012. Autoimmunity initiates in nonhematopoietic cells and progresses via lymphocytes in an interferon-dependent autoimmune disease. Immunity 36: $120-131$.

Gao D, Wu J, Wu Y-T, Du F, Aroh C, Yan N, Sun L, Chen ZJ. 2013. Cyclic GMP-AMP synthase is an innate immune sensor of HIV and other retroviruses. Science 341: $903-$ 906.

Gavrieli Y, Sherman Y, Ben-Sasson SA. 1992. Identification of programmed cell death in situ via specific labeling of nuclear DNA fragmentation. J Cell Biol 119: 493-501.

Gómez-Benito M, Balsas P, Carvajal-Vergara X, Pandiella A, Anel A, Marzo I, Naval J. 2007. Mechanism of apoptosis induced by IFN- $\alpha$ in human myeloma cells: Role of Jak1 and Bim and potentiation by rapamycin. Cell Signal 19: 844-854.

Hanayama R, Tanaka M, Miwa K, Shinohara A, Iwamatsu A, Nagata S. 2002. Identification of a factor that links apoptotic cells to phagocytes. Nature 417: 182-187.

Höss M, Robins P, Naven TJ, Pappin DJ, Sgouros J, Lindahl T. 1999. A human DNA editing enzyme homologous to the Escherichia coli DnaQ/MutD protein. EMBO J 18: 3868-3875.

Ishikawa H, Barber GN. 2008. STING is an endoplasmic reticulum adaptor that facilitates innate immune signalling. Nature 455: 674-678.

Ishikawa H, Ma Z, Barber GN. 2009. STING regulates intracellular DNA-mediated, type I interferon-dependent innate immunity. Nature 461: 788-792.

Jacobson MD, Weil M, Raff MC. 1997. Programmed cell death in animal development. Cell 88: 347-354.

Jain MK, Zoellner C. 2010. Role of ribavirin in HCV treatment response: Now and in the future. Expert Opin Pharmacother 11: 673-683.

Jog NR, Frisoni L, Shi Q, Monestier M, Hernandez S, Craft J, Prak ETL, Caricchio R. 2012. Caspase-activated DNase is required for maintenance of tolerance to lupus nuclear autoantigens. Arthritis Rheum 64: 1247-1256.

Kawane K, Fukuyama H, Kondoh G, Takeda J, Ohsawa Y, Uchiyama Y, Nagata S. 2001. Requirement of DNase II for 
K. Kawane et al.

definitive erythropoiesis in the mouse fetal liver. Science 292: $1546-1549$.

Kawane K, Fukuyama H, Yoshida H, Nagase H, Ohsawa Y, Uchiyama Y, Okada K, Iida T, Nagata S. 2003. Impaired thymic development in mouse embryos deficient in apoptotic DNA degradation. Nat Immunol 4: 138-144.

Kawane K, Ohtani M, Miwa K, Kizawa T, Kanbara Y, Yoshioka Y, Yoshikawa H, Nagata S. 2006. Chronic polyarthritis caused by mammalian DNA that escapes from degradation in macrophages. Nature 443: 998-1002.

Kawane K, Tanaka H, Kitahara Y, Shimaoka S, Nagata S. 2010. Cytokine-dependent but acquired immunity-independent arthritis caused by DNA escaped from degradation. Proc Natl Acad Sci 107: 19432-19437.

Keffer J, Probert L, Cazlaris H, Georgopoulos S, Kaslaris E, Kioussis D, Kollias G. 1991. Transgenic mice expressing human tumour necrosis factor: A predictive genetic model of arthritis. EMBO J 10: 4025-4031.

Kinchen JM, Ravichandran KS. 2007. Journey to the grave: Signaling events regulating removal of apoptotic cells. $J$ Cell Sci 120: 2143-2149.

Kitano M, Nakaya M, Nakamura T, Nagata S, Matsuda M. 2008. Imaging of Rab5 activity identifies essential regulators for phagosome maturation. Nature 453: 241-245.

Krieser R, MacLea K, Longnecker D, Fields J, Fiering S, Eastman A. 2002. Deoxyribonuclease II $\alpha$ is required during the phagocytic phase of apoptosis and its loss causes perinatal lethality. Cell Death Differ 9: 956-962.

Leventis PA, Grinstein S. 2010. The distribution and function of phosphatidylserine in cellular membranes. Аnnu Rev Biophys 39: 407-427.

Li LY, Luo X, Wang X. 2001. Endonuclease G is an apoptotic DNase when released from mitochondria. Nature 412: 95-99.

Li XD, Wu J, Gao D, Wang H, Sun L, Chen ZJ. 2013. Pivotal roles of cGAS-cGAMP signaling in antiviral defense and immune adjuvant effects. Science 341: 1390-1394.

Liu X, Zou H, Slaughter C, Wang X. 1997. DFF, a heterodimeric protein that functions downstream of caspase- 3 to trigger DNA fragmentation during apoptosis. Cell 89: $175-184$.

Mahrus S, Trinidad JC, Barkan DT, Sali A, Burlingame AL, Wells JA. 2008. Global sequencing of proteolytic cleavage sites in apoptosis by specific labeling of protein $\mathrm{N}$ termini. Cell 134: 866-876.

McAvoy JW, Chamberlain CG, de Iongh RU, Hales AM, Lovicu FJ. 1999. Lens development. Eye 13: 425-437.

McDermott-Roe C, Ye J, Ahmed R, Sun X-M, Serafín A, Ware J, Bottolo L, Muckett P, Cañas X, Zhang J, et al. 2011. Endonuclease $G$ is a novel determinant of cardiac hypertrophy and mitochondrial function. Nature 478: 114-118.

McGrath K, Kingsley P, Koniski A, Porter R, Bushnell T, Palis J. 2008. Enucleation of primitive erythroid cells generates a transient population of "pyrenocytes" in the mammalian fetus. Blood 111: 2409-2417.

McIlroy D, Tanaka M, Sakahira H, Fukuyama H, Suzuki M, Yamamura K, Ohsawa Y, Uchiyama Y, Nagata S. 2000. An auxiliary mode of apoptotic DNA fragmentation provided by phagocytes. Genes Dev 14: 549-558.
Medzhitov R. 2007. Recognition of microorganisms and activation of the immune response. Nature 449: 819826.

Miyanishi M, Tada K, Koike M, Uchiyama Y, Kitamura T, Nagata S. 2007. Identification of Tim 4 as a phosphatidylserine receptor. Nature 450: 435-439.

Mizuta R, Mizuta M, Araki S, Suzuki K, Ebara S, Furukawa Y, Shiokawa D, Tanuma S, Kitamura D. 2009. DNase $\gamma$ dependent and -independent apoptotic DNA fragmentations in Ramos Burkitt's lymphoma cell line. Biomed Res 30: 165-170.

Morita M, Stamp G, Robins P, Dulic A, Rosewell I, Hrivnak G, Daly G, Lindahl T, Barnes DE. 2004. Gene-targeted mice lacking the Trexl (DNase III) $3^{\prime} \rightarrow 5^{\prime}$ DNA exonuclease develop inflammatory myocarditis. Mol Cell Biol 24: 6719-6727.

Mukae N, Enari M, Sakahira H, Fukuda Y, Inazawa J, Toh H, Nagata S. 1998. Molecular cloning and characterization of human caspase-activated DNase. Proc Natl Acad Sci 95: 9123-9128.

Mukae N, Yokoyama H, Yokokura T, Sakoyama Y, Nagata S. 2002. Activation of the innate immunity in Drosophila by endogenous chromosomal DNA that escaped apoptotic degradation. Genes Dev 16: 2662-2671.

Nagase H, Fukuyama H, Tanaka M, Kawane K, Nagata S. 2003. Mutually regulated expression of caspase-activated DNase and its inhibitor for apoptotic DNA fragmentation. Cell Death Differ 10: 142-143.

Nagata S. 1997. Apoptosis by death factor. Cell 88: 355-365.

Nagata S. 2005. DNA degradation in development and programmed cell death. Annu Rev Immunol 23: 853-875.

Nakahara M, Nagasaka A, Koike M, Uchida K, Kawane K, Uchiyama Y, Nagata S. 2007. Degradation of nuclear DNA by DNase II-like acid DNase in cortical fiber cells of mouse eye lens. FEBS J 274: 3055-3064.

Nakaya M, Kitano M, Matsuda M, Nagata S. 2008. Spatiotemporal activation of Racl for engulfment of apoptotic cells. Proc Natl Acad Sci 105: 9198-9203.

Napirei M, Wulf S, Mannherz H. 2004. Chromatin breakdown during necrosis by serum Dnase 1 and the plasminogen system. Arthritis Rheum 50: 1873-1883.

Nishimoto S, Kawane K, Watanabe-Fukunaga R, Fukuyama H, Ohsawa Y, Uchiyama Y, Hashida N, Ohguro N, Tano Y, Morimoto T, et al. 2003. Nuclear cataract caused by a lack of DNA degradation in the mouse eye lens. Nature 424: 1071-1074.

Oka T, Hikoso S, Yamaguchi O, Taneike M, Takeda T, Tamai T, Oyabu J, Murakawa T, Nakayama H, Nishida K, et al. 2012. Mitochondrial DNA that escapes from autophagy causes inflammation and heart failure. Nature 485: 251 255.

Okabe Y, Kawane K, Akira S, Taniguchi T, Nagata S. 2005. Toll-like receptor-independent gene induction program activated by mammalian DNA escaped from apoptotic DNA degradation. J Exp Med 202: 1333-1339.

Okabe Y, Kawane K, Nagata S. 2008. IFN regulatory factor (IRF) 3/7-dependent and -independent gene induction by mammalian DNA that escapes degradation. Eur J Immunol 38: 3150-3158. 
Okabe Y, Sano T, Nagata S. 2009. Regulation of the innate immune response by threonine-phosphatase of eyes absent. Nature 460: 520-524.

O’Neill LAJ. 2013. Immunology. Sensing the dark side of DNA. Science 339: 763-764.

Ostertag EM, Kazazian HH. 2001. Biology of mammalian L1 retrotransposons. Annu Rev Genet 35: 501-538.

Palis J. 2008. Ontogeny of erythropoiesis. Curr Opin Hematol 15: 155-161.

Paludan SR, Bowie AG. 2013. Immune sensing of DNA. Immunity 38: 870-880.

Park D, Tosello-Trampont AC, Elliott MR, Lu M, Haney LB, Ma Z, Klibanov AL, Mandell JW, Ravichandran KS. 2007 BAIl is an engulfment receptor for apoptotic cells upstream of the ELMO/Dock180/Rac module. Nature 450: 430-434.

Park SY, Jung MY, Kim HJ, Lee SJ, Kim SY, Lee BH, Kwon TH, Park RW, Kim IS. 2008. Rapid cell corpse clearance by stabilin-2, a membrane phosphatidylserine receptor. Cell Death Differ 15: 192-201.

Penninger JM, Kroemer G. 2003. Mitochondria, AIF and caspases-Rivaling for cell death execution. Nat Cell Biol 5: 97-99.

Prak ET, Kazazian HH. 2000. Mobile elements and the human genome. Nat Rev Genet 1: 134-144.

Rathinam VAK, Jiang Z, Waggoner SN, Sharma S, Cole LE, Waggoner L, Vanaja SK, Monks BG, Ganesan S, Latz E, et al. 2010. The AIM2 inflammasome is essential for host defense against cytosolic bacteria and DNA viruses. Nat Immunol 11: 395-402.

Rekvig OP, Mortensen ES. 2012. Immunity and autoimmunity to dsDNA and chromatin-The role of immunogenic DNA-binding proteins and nuclease deficiencies. Autoimmunity 45: 588-592.

Rhodes MM, Kopsombut P, Bondurant MC, Price JO, Koury MJ. 2008. Adherence to macrophages in erythroblastic islands enhances erythroblast proliferation and increases erythrocyte production by a different mechanism than erythropoietin. Blood 111: 1700-1708.

Ronald PC, Beutler B. 2010. Plant and animal sensors of conserved microbial signatures. Science 330: 1061-1064.

Sakahira H, Nagata S. 2002. Co-translational folding of caspase-activated DNase with Hsp70, Hsp40 and inhibitor of caspase-activated DNase. J Biol Chem 277: 3364-3370.

Sakahira H, Enari M, Nagata S. 1998. Cleavage of CAD inhibitor in CAD activation and DNA degradation during apoptosis. Nature 391: 96-99.

Sakahira H, Iwamatsu A, Nagata S. 2000. Specific chaperone-like activity of inhibitor of caspase-activated DNase for caspase-activated DNase. J Biol Chem 275: 80918096.

Sassaman DM, Dombroski BA, Moran JV, Kimberland ML, Naas TP, DeBerardinis RJ, Gabriel A, Swergold GD, Kazazian HH. 1997. Many human L1 elements are capable of retrotransposition. Nat Genet 16: 37-43.

Scott RS, McMahon EJ, Pop SM, Reap EA, Caricchio R, Cohen PL, Earp HS, Matsushima GK. 2001. Phagocytosis and clearance of apoptotic cells is mediated by MER. Nature 411: 207-211.

Scott D, Wolfe F, Huizinga T. 2010. Rheumatoid arthritis. Lancet 376: 1094-1108.
Shiokawa D, Tanuma S. 1999. DLAD, a novel mammalian divalent cation-independent endonuclease with homology to DNase II. Nucleic Acids Res 27: 4083-4089.

Stetson DB, Ko JS, Heidmann T, Medzhitov R. 2008. Trex1 prevents cell-intrinsic initiation of autoimmunity. Cell 134: $587-598$.

Strasser A, Jost PJ, Nagata S. 2009. The many roles of FAS receptor signaling in the immune system. Immunity 30: $180-192$.

Su DM, Wang J, Lin Q, Cooper MD, Watanabe T. 1997. Interferons $\alpha / \beta$ inhibit IL-7-induced proliferation of $\mathrm{CD} 4^{-} \mathrm{CD} 8^{-} \mathrm{CD}^{-} \mathrm{CD} 44^{+} \mathrm{CD} 25^{+}$thymocytes, but do not inhibit that of $\mathrm{CD} 4^{-} \mathrm{CD} 8^{-} \mathrm{CD} 3^{-} \mathrm{CD} 44^{-} \mathrm{CD} 25^{-}$ thymocytes. Immunology 90: 543-549.

Sun L, Wu J, Du F, Chen X, Chen ZJ. 2013. Cyclic GMP-AMP synthase is a cytosolic DNA sensor that activates the type I interferon pathway. Science 339: 786-791.

Susin SA, Daugas E, Ravagnan L, Samejima K, Zamzami N, Loeffler M, Costantini P, Ferri KF, Irinopoulou T, Prevost MC, et al. 2000. Two distinct pathways leading to nuclear apoptosis. J Exp Med 192: 571-580.

Suzuki J, Denning DP, Imanishi E, Horvitz HR, Nagata S. 2013. Xk-related protein 8 and CED-8 promote phosphatidylserine exposure in apoptotic cells. Science 341: 403406.

Takeuchi O, Akira S. 2010. Pattern recognition receptors and inflammation. Cell 140: 805-820.

Tanaka Y, Chen ZJ. 2012. STING specifies IRF3 phosphorylation by TBK1 in the cytosolic DNA signaling pathway. Sci Signal 5: ra20-ra20.

Tang HL, Tang HM, Mak KH, Hu S, Wang SS, Wong KM, Wong CST, Wu HY, Law HT, Liu K, et al. 2012. Cell survival, DNA damage, and oncogenic transformation after a transient and reversible apoptotic response. $\mathrm{Mol}$ Biol Cell 23: 2240-2252.

Terman A, Kurz T, Gustafsson B, Brunk UT. 2006. Lysosomal labilization. IUBMB Life 58: 531-539.

Toda S, Hanayama R, Nagata S. 2012. Two-step engulfment of apoptotic cells. Mol Cell Biol 32: 118-125.

Vastert SJ, Kuis W, Grom AA. 2009. Systemic JIA: New developments in the understanding of the pathophysiology and therapy. Best Pract Res Clin Rheumatol 23: 655-664.

von Figura K, Hasilik A. 1986. Lysosomal enzymes and their receptors. Annu Rev Biochem 55: 167-193.

Woo E-J, Kim Y-G, Kim M-S, Han W-D, Shin S, Robinson H, Park S-Y, Oh B-H. 2004. Structural mechanism for inactivation and activation of CAD/DFF40 in the apoptotic pathway. Mol Cell 14: 531-539.

Wu YC, Stanfield GM, Horvitz HR. 2000. NUC -1 , a Caenorhabditis elegans DNase II homolog, functions in an intermediate step of DNA degradation during apoptosis. Genes Dev 14: 536-548.

Wu J, Sun L, Chen X, Du F, Shi H, Chen C, Chen ZJ. 2013. Cyclic GMP-AMP is an endogenous second messenger in innate immune signaling by cytosolic DNA. Science 339: 826-830.

Wyllie AH. 1980. Glucocorticoid-induced thymocyte apoptosis is associated with endogenous endonuclease activation. Nature 284: 555-556. 


\section{K. Kawane et al.}

Xiao TS, Fitzgerald KA. 2013. The cGAS-STING pathway for DNA sensing. Mol Cell 51: 135-139.

Xiong W, Chen Y, Wang H, Wu H, Lu Q, Han D. 2008. Gas6 and the Tyro 3 receptor tyrosine kinase subfamily regulate the phagocytic function of Sertoli cells. Reproduction 135: $77-87$.

Yan B, Wang H, Peng Y, Hu Y, Wang H, Zhang X, Chen Q, Bedford JS, Dewhirst MW, Li C-Y. 2006. A unique role of the DNA fragmentation factor in maintaining genomic stability. Proc Natl Acad Sci 103: 1504-1509.

Yan N, Regalado-Magdos A, Stiggelbout B, Lee-Kirsch M, Lieberman J. 2010. The cytosolic exonuclease TREX1 inhibits the innate immune response to human immunodeficiency virus type 1. Nat Immunol 11: 1005-1013.

Yang HW, Chen YZ, Piao HY, Takita J, Soeda E, Hayashi Y. 2001. DNA fragmentation factor 45 (DFF45) gene at 1 p36.2 is homozygously deleted and encodes variant transcripts in neuroblastoma cell line. Neoplasia 3: $165-169$.

Yasutomo K, Horiuchi T, Kagami S, Tsukamoto H, Hashimura C, Urushihara M, Kuroda Y. 2001. Mutation of DNASE1 in people with systemic lupus erythematosus. Nat Genet 28: 313-314.

Yoshida H, Kawane K, Koike M, Mori Y, Uchiyama Y, Nagata S. 2005a. Phosphatidylserine-dependent engulfment by macrophages of nuclei from erythroid precursor cells. Nature 437: 754-758.

Yoshida H, Okabe Y, Kawane K, Fukuyama H, Nagata S. 2005b. Lethal anemia caused by interferon- $\beta$ produced in mouse embryos carrying undigested DNA. Nat Immunol 6: 49-56.

Zhang J, Liu X, Scherer DC, van Kaer L, Wang X, Xu M. 1998. Resistance to DNA fragmentation and chromatin condensation in mice lacking the DNA fragmentation factor 45. Proc Natl Acad Sci 95: 12480-12485. 


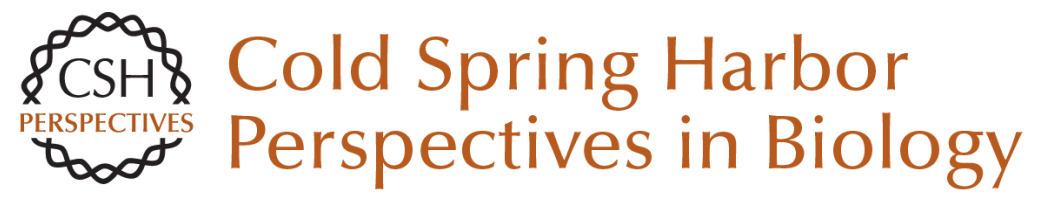

\section{DNA Degradation and Its Defects}

Kohki Kawane, Kou Motani and Shigekazu Nagata

Cold Spring Harb Perspect Biol 2014; doi: 10.1101/cshperspect.a016394

Subject Collection Innate Immunity and Inflammation

Group 2 Innate Lymphoid Cells in Health and

Disease

Brian S. Kim and David Artis

Inflammation and the Blood Microvascular

System

Jordan S. Pober and William C. Sessa

Sinusoidal Immunity: Macrophages at the

Lymphohematopoietic Interface

Siamon Gordon, Annette Plüddemann and

Subhankar Mukhopadhyay

Allergic Inflammation--Innately Homeostatic Laurence E. Cheng and Richard M. Locksley

Approaching the Next Revolution? Evolutionary Integration of Neural and Immune Pathogen

Sensing and Response

Kevin J. Tracey

Inflammasomes

Marcel R. de Zoete, Noah W. Palm, Shu Zhu, et al.

IL-6 in Inflammation, Immunity, and Disease Toshio Tanaka, Masashi Narazaki and Tadamitsu Kishimoto
The Chemokine System in Innate Immunity Caroline L. Sokol and Andrew D. Luster

Microbial Sensing by Toll-Like Receptors and Intracellular Nucleic Acid Sensors

Surya Pandey, Taro Kawai and Shizuo Akira

Tumor Necrosis Factor Superfamily in Innate Immunity and Inflammation John Sedý, Vasileios Bekiaris and Carl F. Ware

\section{Emerging Principles Governing Signal} Transduction by Pattern-Recognition Receptors Jonathan C. Kagan and Gregory M. Barton

Lipid Mediators in the Resolution of Inflammation Charles N. Serhan, Nan Chiang, Jesmond Dalli, et al.

\section{Transcriptional Control of Inflammatory} Responses

Stephen T. Smale and Gioacchino Natoli

DNA Degradation and Its Defects

Kohki Kawane, Kou Motani and Shigekazu Nagata

For additional articles in this collection, see http://cshperspectives.cshlp.org/cgi/collection/

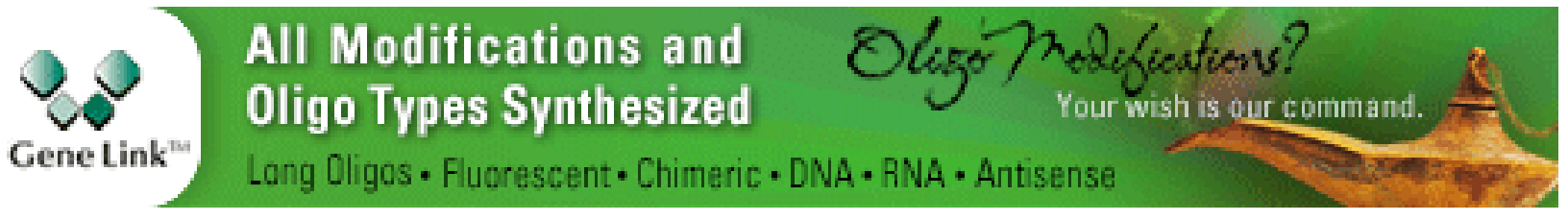

Copyright @ 2014 Cold Spring Harbor Laboratory Press; all rights reserved 